\title{
Flexible Bistable Smectic-A Liquid Crystal Device Using Photolithography and Photoinduced Phase Separation
}

\author{
Yang Lu, Jinbao Guo, Hao Wang, and Jie Wei \\ College of Materials Science and Engineering, Beijing University of Chemical Technology, Beijing 100029, China \\ Correspondence should be addressed to Jinbao Guo, guojb@mail.buct.edu.cn and Jie Wei, weijie-2008@hotmail.com
}

Received 31 March 2012; Accepted 20 September 2012

Academic Editor: Victor V. Moshchalkov

Copyright () 2012 Yang Lu et al. This is an open access article distributed under the Creative Commons Attribution License, which permits unrestricted use, distribution, and reproduction in any medium, provided the original work is properly cited.

A flexible bistable smectic-A liquid crystal (SmA LC) device using pixel-isolated mode was demonstrated, in which SmA LC molecules were isolated in pixels by vertical polymer wall and horizontal polymer layer. The above microstructure was achieved by using ultraviolet (UV) photolithography and photoinduced phase separation. The polymer wall was fabricated by photolithography, and then the SmA LC was encapsulated in pixels between polymer wall through UV-induced phase separation, in which the polymer wall acts as supporting structure from mechanical pressure and maintains the cell gap from bending, and the polymer layer acts as adhesive for tight attachment of two substrates. The results demonstrated that all the intrinsic bistable properties of the SmA LC are preserved, and good electrooptical characteristics such as high contrast ratio and excellent stability of the bistable states were characterized. This kind of SmA bistable flexible display has high potential to be used as electronic paper, smart switchable reflective windows, and so forth.

\section{Introduction}

Bistable liquid crystal (LC) devices have been extensively investigated and used for display applications because of their unique electrooptic properties, mainly the ability to maintain an image indefinitely without power consumption [1-9]. Many ways have been developed to produce bistable LC devices over the past years [10]. Among them, a bistable display utilizing an ion-doped smectic-A (SmA) LCs is of great interest because of its potential applications as low-power and low-cost display devices, switchable storage devices, and electronic paper [11]. Ion-doped SmA LC devices retain two electrically switchable zero field stable optical states: (1) a transparent homeotropic state generated through dielectric reorientation of molecules at high frequency $(>1 \mathrm{kHz})$ alternating current (AC) electric fields and (2) a scattering focal conic state generated through electrohydrodynamic instability (EHDI) at low-frequency $(<1 \mathrm{kHz})$ electric fields. Compared to other bistable displays, bistable SmA display offers a more simplified display mode, long-term stability, and an excellent contrast, since bistable SmA LC devices do not require polarizers or backlights leading to energy efficiency when compared to the twisted nematic (TN) or supertwisted nematic (STN) displays [12].

In the recent decades, more research efforts have been focused on the bistable SmA LC display technology of plastic substrates for potential use in flexible display applications [13-16]. The possibility of fabricating flexible liquid crystal films on plastic substrates is challenging because of the difficulty maintaining uniform thickness, preventing air bubble formation and mechanical stability after bending. To solve these problems, several types of polymer wall and/or network as supporting structures have been proposed and demonstrated [17-21]. These structures were fabricated using an anisotropic phase separation method from polymer and SmA LC composite systems by applying a patterned electric field or spatially modulated ultraviolet (UV) intensity [2224]. However, these methods require high electric field to initiate the anisotropic phase separation or remain residual polymers in unexposed regions that reduce optical properties and increase the operating voltage of the devices. Therefore, these methods are not appropriate to a cost-effective rollto-roll process, which is essential to fabricate large area 
(1) Smectic-A LC

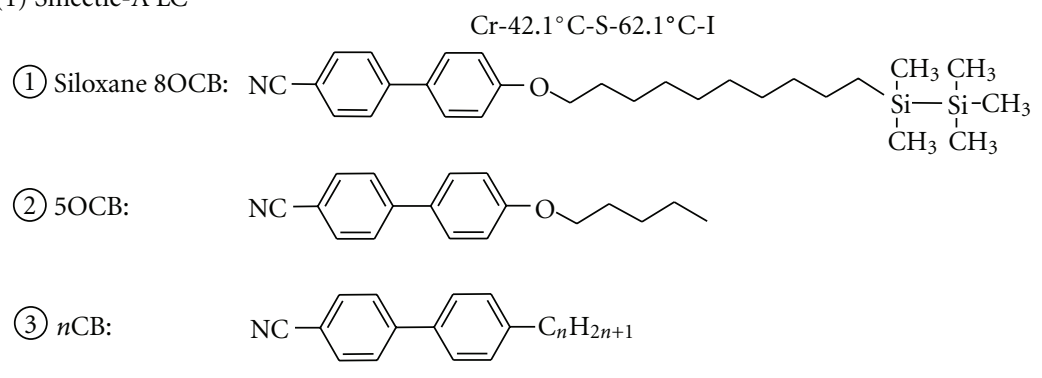

(4) Hexadecyl trimethyl ammonium bromide

Siloxane 8OCB: $20 \mathrm{wt} \%$, 5OCB: $5 \mathrm{wt} \%, n=8: 55 \mathrm{wt} \%$,

$n=10: 10 \mathrm{wt} \%, n=12: 10 \mathrm{wt} \%$, CTAB: $0.1 \mathrm{wt} \%$

(2) Photoinitiator: 2,2-dimethoxy-2-phenyl-acetophenone (TCI Co. Ltd.)

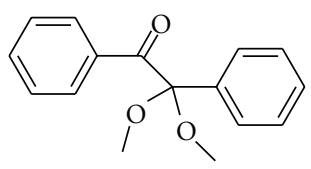

(3) Dye: G168 (Mitsubishi Chemical Corporation)

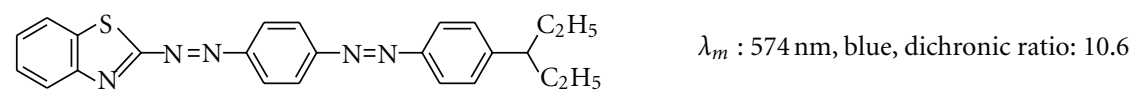

Figure 1: Molecule structures of LCs, photoinitiator, and azo dichroic dye.

plastic LCDs. Thus, an alternate fabrication method should be developed for the plastic LCDs to be commercialized.

Herein, we reported fabrication of a pixel-isolated polymer wall structure of a flexible bistable SmA LC device by using photolithography and photoinduced phase separation. The polymer wall was fabricated by UV photolithography, and the upper layer was formed by UV-induced monomers diffusion to the upper layer during UV irradiation, resulting in SmA LC being surrounded by the interpixel vertical polymer walls and the horizontal polymer film. The electrooptic properties of this flexible bistable SmA LC device have been studied as a function of monomer concentration, frequency, and the applied voltage. Additionally, the effect of dichroic dye on the electrooptic characteristics has also been discussed.

\section{Experimental}

2.1. Materials. In this study, oligomer SB510E35, molecular additives of monomer SR423 and monomer SR238 (Sartomer USA, LLC), photoinitiator, 2, 2-dimethoxy-2phenyl-acetophenone (Irgacure 651, TCI Co. Ltd.), 4' -octyl4-biphenylnitrile (8CB, nematic liquid crystal, $\mathrm{Cr}-21.5^{\circ} \mathrm{C}$ S-33.5 $\left.{ }^{\circ} \mathrm{C}-\mathrm{N}-40.5^{\circ} \mathrm{C}-\mathrm{I}\right), \quad 4^{\prime}$-decyl-4-biphenylnitrile $\quad(10 \mathrm{CB}$, Cr-44.5 ${ }^{\circ} \mathrm{C}-\mathrm{S}-50.5^{\circ} \mathrm{C}-\mathrm{I}$ ), $4^{\prime}$-dodecyl-4-biphenylnitrile (12CB, $\left.\mathrm{Cr}-48^{\circ} \mathrm{C}-\mathrm{S}-58.5^{\circ} \mathrm{C}-\mathrm{I}\right), \quad 4^{\prime}$-pentamethoxyl-4-biphenylnitrile
(5OCB, $\left.\quad \mathrm{Cr}-48^{\circ} \mathrm{C}-\mathrm{N}-68^{\circ} \mathrm{C}-\mathrm{I}\right)$, pentamethyl siloxane- $4^{\prime}-$ decyloxy-4-biphenylnitile (siloxane $8 \mathrm{OCB}, \mathrm{Cr}-42.1^{\circ} \mathrm{C}-\mathrm{S}$ $62.1^{\circ} \mathrm{C} / \mathrm{I}$ ), hexadecyl trimethyl ammonium bromide (CTAB, used as ion additive) were used, the $8 \mathrm{CB}, 10 \mathrm{CB}, 12 \mathrm{CB}, 5 \mathrm{OCB}$ were purchased from Shijiazhuang Sdyano fine chemical Co., Ltd, and siloxane LC was synthesized according to the method suggested by Newton et al. [25, 26]. All molecule structures of the materials used in this study were shown in Figure 1.

2.2. Preparation of Flexible Bistable SmA LC Device. The negative photoresist (50 wt\% SB510E35, $25 \mathrm{wt} \%$ SR423, $25 \mathrm{wt} \%$ SR238) with $4 \mathrm{wt} \%$ Irgacure 651 was coated on flexible PET substrate uniformly and heated at $80^{\circ} \mathrm{C}$ for $2 \mathrm{~h}$; then the photoresist coating was selectively exposed by UV illumination through square array-patterned chromium plate to fabricate polymer wall. The photoresist was etched by developer (sodium carbonate solution, $0.4 \mathrm{wt} \%$ ) to reveal the patterned polymer wall with the uniform thickness of $12 \mu \mathrm{m}$.

The ion-doped smectic-A liquid crystal was prepared by mixing siloxane $8 \mathrm{OCB}(20 \mathrm{wt} \%), 8 \mathrm{CB}(55 \mathrm{wt} \%), 10 \mathrm{CB}$ $(10 \mathrm{wt} \%), 12 \mathrm{CB}(10 \mathrm{wt} \%), 5 \mathrm{OCB}(5 \mathrm{wt} \%)$, and CTAB $(0.1 \mathrm{wt} \%)$. The mixture was $\mathrm{LC}$ at phase of smectic A, and the clearing point is about $47^{\circ} \mathrm{C}$; then approximate $1 \sim$ $20 \mathrm{wt} \%$ molecular additives (SR423/SR238 = 4/1, with $4 \mathrm{wt} \%$ Irgacure 651) were added into the liquid crystal, and the 
$\mathrm{SmA} /$ molecular additive mixture was filled into the blanks on polymer wall substrate at temperature above the clearing point of SmA LC. Then the upper substrate was covered onto the polymer wall to fabricate a sandwich-like device, air bubble can be prevented by mobility of the mixture before bonding of two substrates. After the device was exposed in UV irradiation at room temperature, within the irradiation process, monomer additives in the mixture moved to the top area in low UV intensity and polymerized to polymer layer in high UV intensity. Polymer layer cemented the upper substrate with the polymer wall.

2.3. Measurements. RT-IR (real-time infrared radiation) spectra were taken on the Nicolet 5700 spectrometer at frequencies ranging from 4000 to $7000 \mathrm{~cm}^{-1}$. Photoresist samples were sandwiched by two glass slides and placed in the IR spectrometer chamber, then exposed to the UV light $(365 \mathrm{~nm})$ at an intensity of $2.0 \mathrm{~mW} / \mathrm{cm}^{2}$ through the quartz window with the aid of an optical fiber cable. Subsequently, the reduction in the IR absorbance of double bonds at specific wavenumber was monitored to determine the reaction rate. The conversion of the carbon double bond at a given time was calculated according to the equation, $\alpha_{w}(t)=\left\{\left(A_{w}\right)_{t 0}-\left(A_{w}\right)_{t}\right\} /\left(A_{w}\right)_{t 0}$, where $w$ is the wavenumber; $\alpha_{w}(t)$ is the conversion of the bond at $w$ wavenumber; $\left(A_{w}\right)_{t}$ is the area of that bond when the sample is irradiated for $t$ time. In this study, we calculated the conversion by the wavenumber at $6160 \mathrm{~cm}^{-1}$ in glass cells. The samples were observed using a polarizing optical microscope (POM) (Leica, DM2500P); the optical images were recorded using Linksys 2.43 software. The transmission spectra were obtained by UV/vis spectrophotometer (Hitachi, U-3010) at normal incidence. The transmittance of a blank cell was normalized to $100 \%$. The electric field is applied to the cells using a signal generator (HT102V4, Halation Photonics Co., Ltd). The morphologies of surface and cross-section of the polymer wall were observed by scanning electron microscopy (SEM) (Hitachi S-4700).

\section{Results and Discussion}

3.1. Fabrication of Polymer Wall. Photoresist was coated on the ITO layer of flexible PET substrate. To measure the conversion of photoresist layer, RT-IR spectra were taken and shown in Figure 2(a). The cross-linking reaction rate of $\mathrm{C}=\mathrm{C}$ double bonds was determined by monitoring the reduction of IR absorbance at about $6160 \mathrm{~cm}^{-1}$ in glass cells, which corresponds to the $\mathrm{C}-\mathrm{H}$ stretching in the $\mathrm{C}=\mathrm{C}$ group. Peak area decreased in the UV irradiation process, and the conversion of $\mathrm{C}=\mathrm{C}$ bonds can be calculated by the peak area decreasing rate through equation: $\alpha_{w}(t)=\left\{\left(A_{w}\right)_{t 0}-\right.$ $\left.\left(A_{w}\right)_{t}\right\} /\left(A_{w}\right)_{t 0}$.

As shown in Figure 2(a), with the exposure time increasing from $0 \mathrm{~s}$ to $100 \mathrm{~s}$, the intensities of bands at $6160 \mathrm{~cm}^{-1}$ decreased dramatically, which results from the loss of $\mathrm{C}=\mathrm{C}$ bonds in the process of photopolymerization. The conversion of $\mathrm{C}=\mathrm{C}$ double bonds increases sharply at the first $15 \mathrm{~s}$, indicating a fast curing reaction of the negative photoresist. After $100 \mathrm{~s}$ UV irradiation, the conversion reached a stable value of about $80 \%$ and can reach a higher conversion by prolonging time but by no means increase up to $100 \%$ because of the viscosity dramatically increasing during the fast curing reaction, as seen in Figure 2(b).

Figures 3(a)-3(e) show the optical microscope images of polymer wall with the same heating, irradiation intensity, and developing conditions but different irradiation times. Polymer wall has insufficient strength in short irradiation time; with time increases, polymer wall is getting broader and thicker, and the appropriate irradiation time is $10 \mathrm{~s}$. The SEM images of the polymer wall (pixel size $300 \mu \mathrm{m}$ ) with irradiation time $10 \mathrm{~s}$ were shown in Figures 3(f) and $3(\mathrm{~g})$, and the image captured in Figure 3(f) shows the cross-section of the polymer wall substrate. As shown, polymer wall has good gradient and uniform thickness, which enable the LC remarkable and uniform display effect after encapsulation. With irradiation time increasing from $1 \mathrm{~s}$ to $30 \mathrm{~s}$, the photoresist coating can get more energy to induce the polymerization. Compared to the sample with $1 \mathrm{~s}$ irradiation, the sample with $30 \mathrm{~s}$ irradiation has solider polymer wall to isolate LC in each pixel. Due to the oxygen inhibition effect in radical UV curing, it also resulted in the thickness disadvantage: polymer wall in longer irradiation time is thicker than that in insufficient irradiation. Polymer wall thickness is determined by coating thickness and irradiation time together.

3.2. Encapsulation of SmA LC. SmA LC was encapsulated in pixels of polymer wall to form polymer wall stabilized liquid crystal (PWSLC) device. Photosensitive monomer mixture with photoinitiator was introduced in the cell to encapsulate the SmA LC by substrates and polymer wall. The photosensitive mixture and the SmA LC are mixed in a ratio of $1: 99$ (monomer accounting for $1 \mathrm{wt} \%$ ) to as high $20: 80$ (monomer accounting for $20 \mathrm{wt} \%$ ), then the mixture was transferred onto the polymer wall substrate at a temperature well above the clearing point of the SmA LC, top substrate was covered on the polymer wall substrate, and the SmA LC was encapsulated in pixels of the cell.

Phase separation is initiated by exposing the cell to UV irradiation in two steps: (1) UV light at low intensity of $0.1 \mathrm{~mW} / \mathrm{cm}^{2}$; the cell was exposed to a collimated beam of UV light for approximately $10 \mathrm{~min}$, and monomers were induced to the upper substrate and polymerized by UV irradiation; (2) UV light at high intensity of $5 \mathrm{~mW} / \mathrm{cm}^{2}$ for approximately $5 \mathrm{~min}$ to make the monomers polymerize sufficiently. Phase separation results in a solidified film of polymer on the substrate closer to the UV source. The encapsulation process was shown in Figure 4(a). Polymer layer was fabricated through this way to adhere the upper substrate to the lower polymer wall substrate; Figure 4(b) is the stereoscopic structure of the cell. To highlight the polymer layer, excessive $30 \mathrm{wt} \%$ monomer was applied in the encapsulation process; the cell was immersed in hexamethylene for $12 \mathrm{~h}$ to remove SmA LC molecules. Figure 4(c) shows the cross-section of a cell without SmA LC. The POM images of transparent and opaque states were shown in Figure 4(d); 


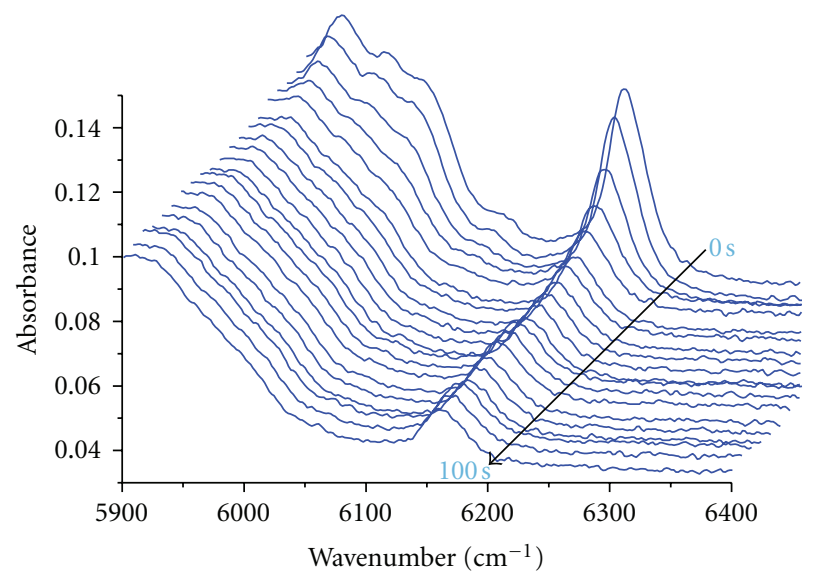

(a)

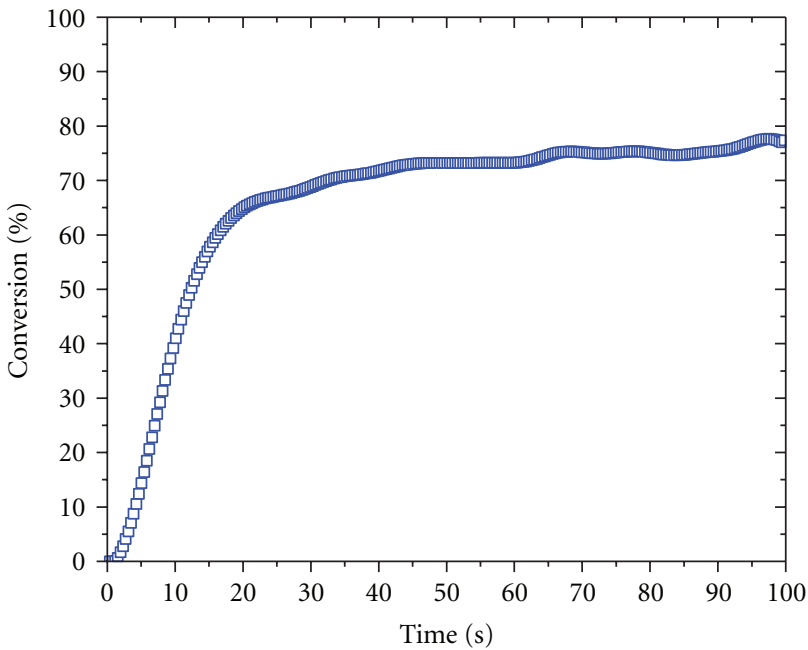

(b)

Figure 2: (a) Real-time IR peak area change and (b) $\mathrm{C}=\mathrm{C}$ bonds conversion.

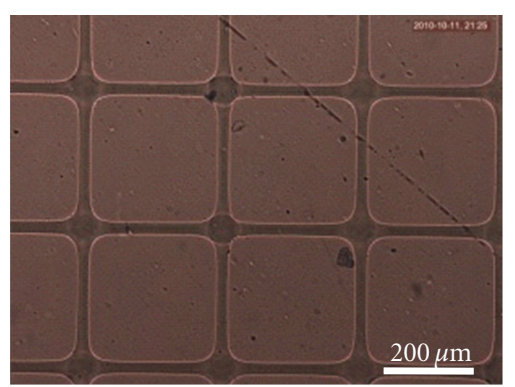

(a)

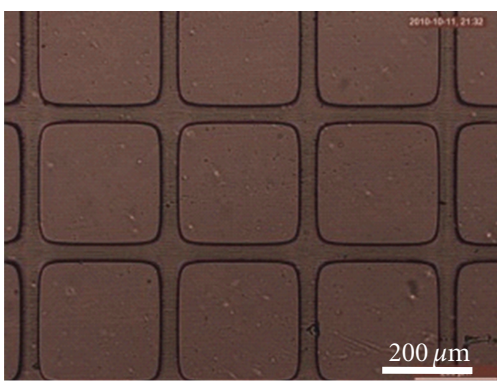

(b)

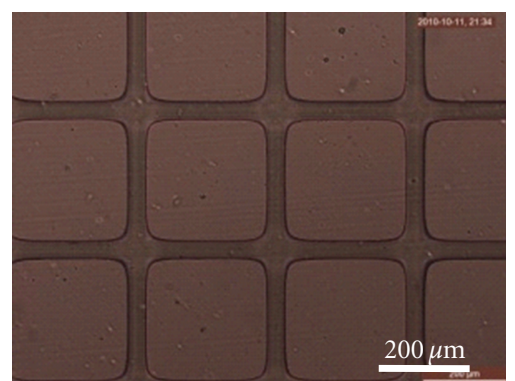

(c)

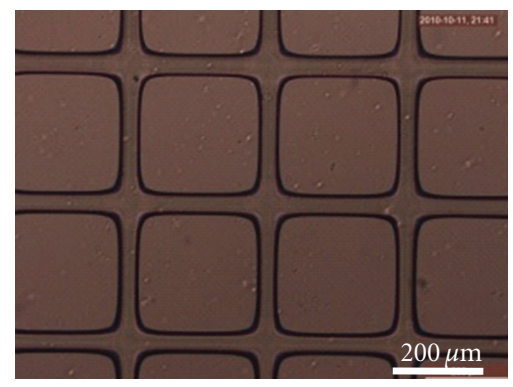

(d)

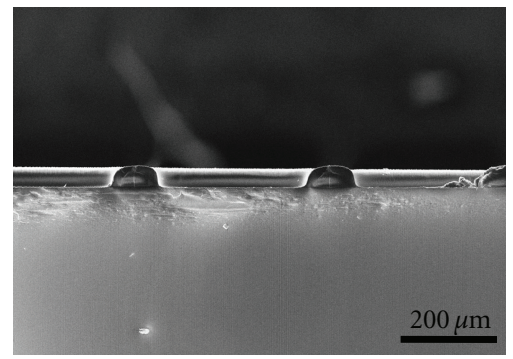

(f)

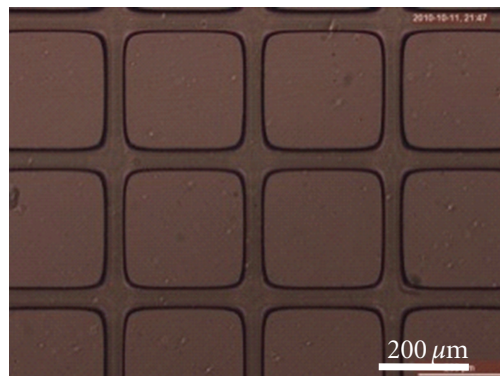

(e)

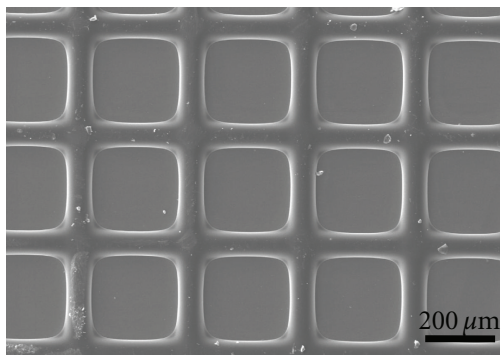

$(\mathrm{g})$

FIgure 3: (a)-(e) Polymer wall surface topography of different illumination time; (f) SEM image of the cross-section of polymer wall; (g) SEM image of the surface morphology of polymer wall. 

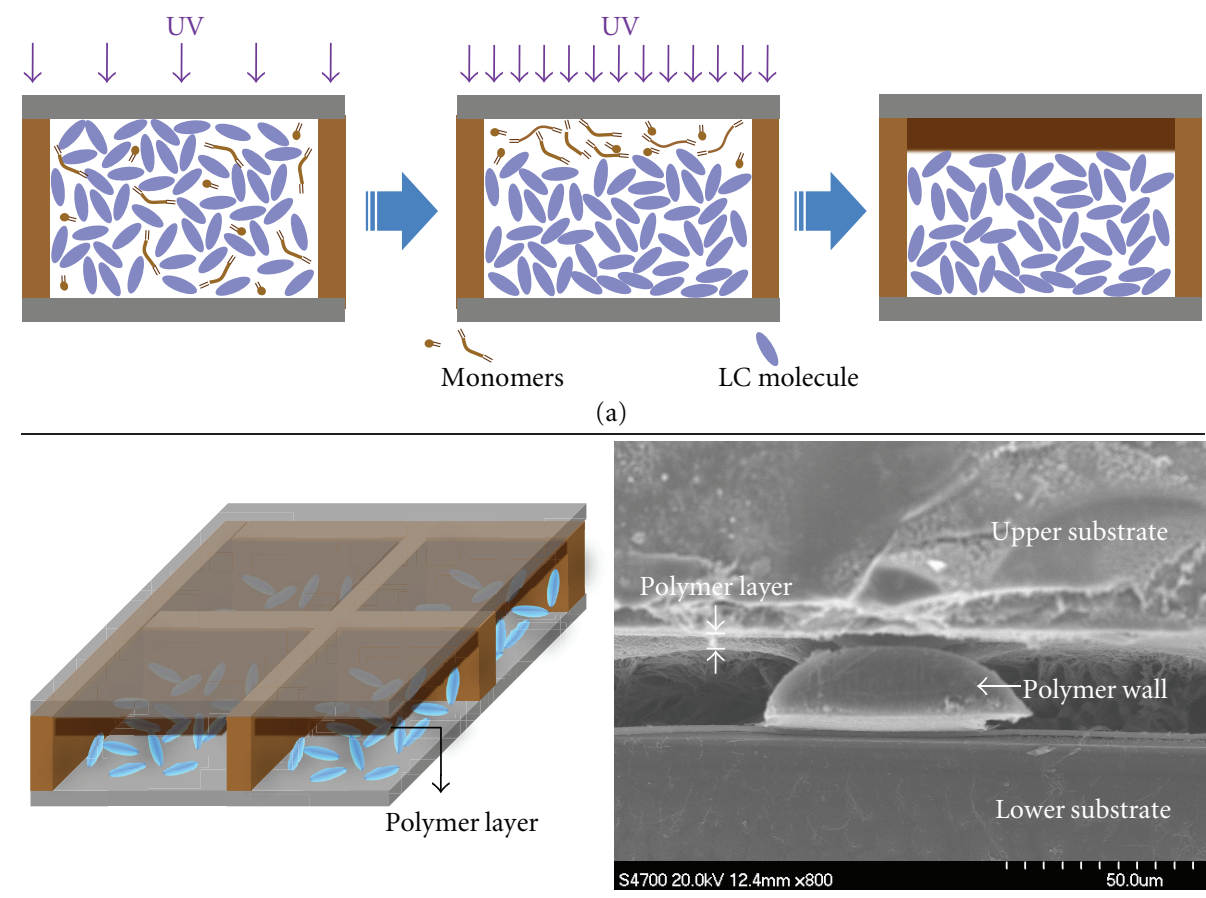

(b)

(c)
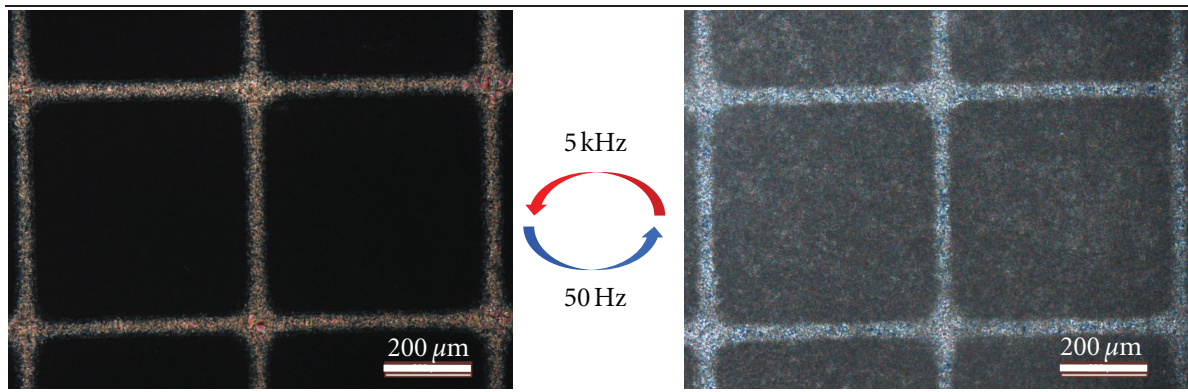

(d)

FIGURE 4: (a) The process of LC/monomer encapsulation; (b) polymer layer in space configuration; (c) SEM image of encapsulated cell by polymer layer; (d) the transparent and opaque states images observed by POM.

it shows the dark field in transparent state and the texture of SmA in opaque state.

3.3. Electric-Optical (EO) Performances of Encapsulated PWSLC. The EO response was detected in UV/VIS spectrophotometer at normal incidence. The electrooptical performances of all the SmA LC cells were measured in the normal transmission geometry at a $5^{\circ}$ collection angle by using the $632 \mathrm{~nm}$ wavelength. Figure 5 shows the static-response characteristics of LC and PWSLC with the same cell spacing thickness of approximately $12 \mu \mathrm{m} .5 \mathrm{kHz}$ square wave of AC field was applied to induce the focal conic-homeotropic (FC$\mathrm{HT}$ ) transition; $50 \mathrm{~Hz}$ square wave of AC field was applied to induce the EHDI transition relatively.

Compared with pure SmA cell, PWSLC cell has different transmissions in both states. Herein, we define transmission difference (TD) as the difference between maximum transmissions of the transparent state and the minimum transmission of the opaque state, and TD of pure SmA cell was named as CR value $100 \%$; therefore the $C R$ value of the cell was defined as the ratio TD of the cell to TD of pure SmA. Mixture of SR423/SR238 (also used in polymer wall fabrication, mass ratio 4/1) was applied as the monomer additive, because of the similar refractive index with polymer wall. Cells with different monomer contents were compared to measure the differences of CR values. Monomer additives were induced by UV illumination and polymerized to polymer layer in the surface of upper substrate in two steps, separately.

Figure 5 also showed the EO curves of PWSLC with different monomer contents range from $0 \%$ (pure SmA, $\mathrm{wt} \%$ ) to 20\%. Both FC-HT (Figure 5(a)) and EHDI (Figure 5(b)) transitions indicate that higher monomer content would result in insufficient transition, which makes $\mathrm{CR}$ value reduced. With monomer content increases, the 


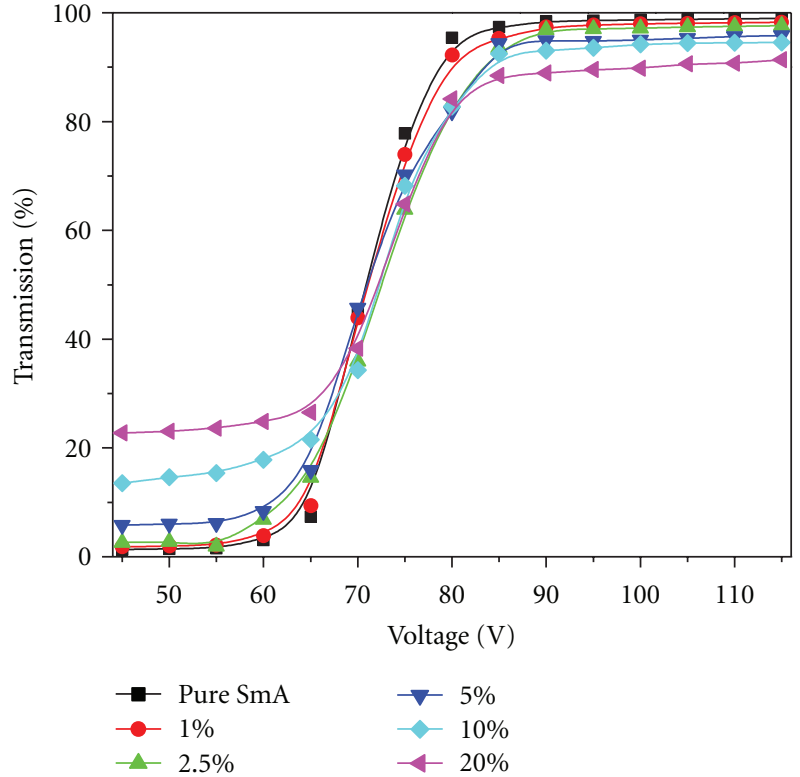

(a)

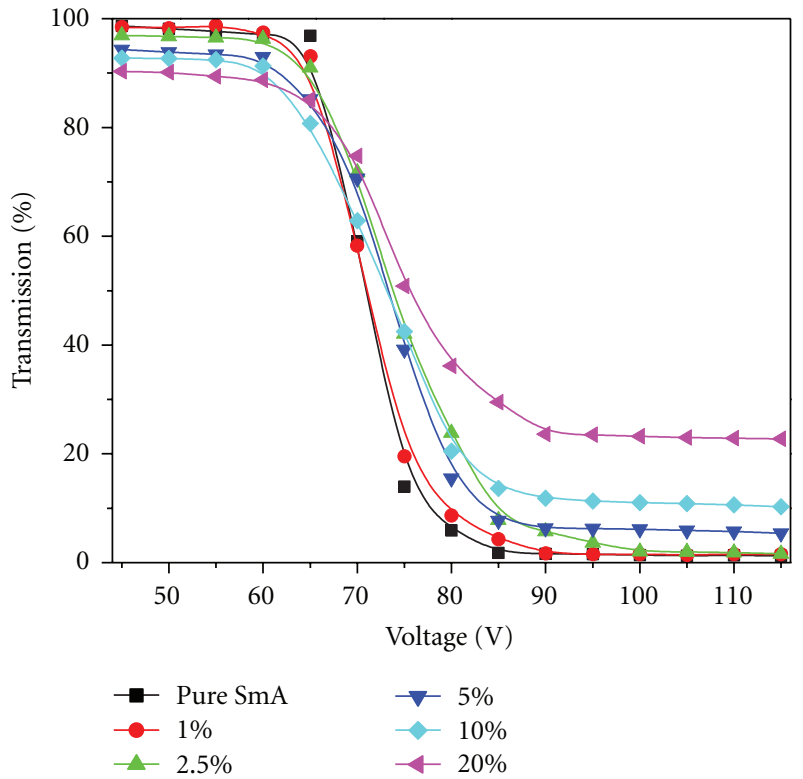

(b)

FIgURE 5: Static-response curves for pure SmA, cell with 1\%, 2.5\%, 5\%, 10\%, 20\% monomer for FC-HT and EHDI transitions at (a) $5 \mathrm{kHz}$ and (b) $50 \mathrm{~Hz}$, respectively.

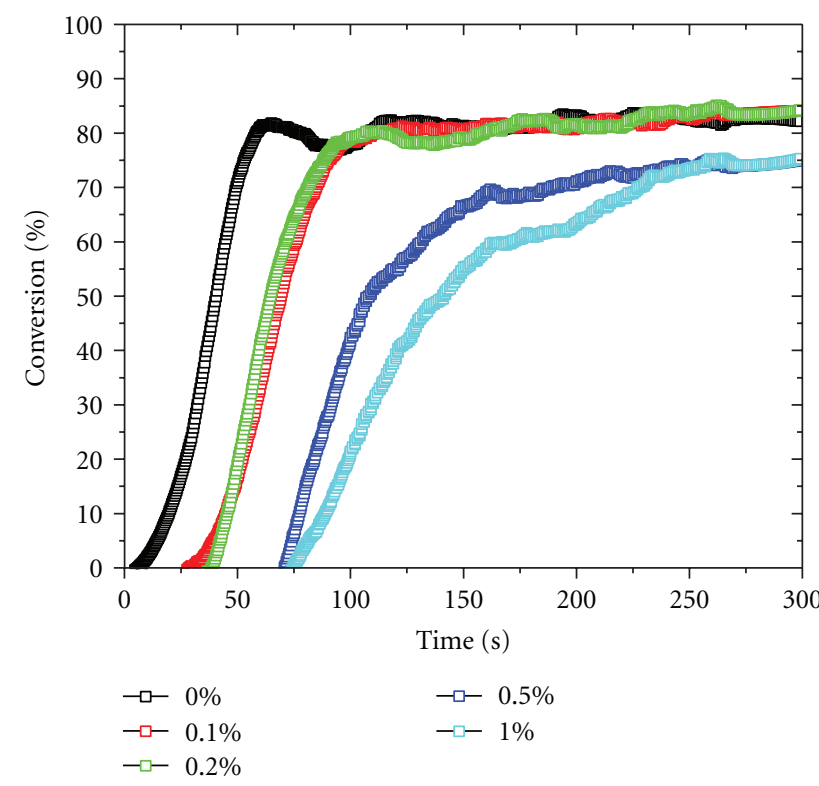

FIGURE 6: The conversion of monomer mixtures with different dye contents.

transmissions of cells at opaque state get significantly higher than that of pure SmA cell. Meanwhile, the transparent state transmission reduced slightly. Thus, we can deduce that more monomers in LC mixture weakened the visual effect of opaque state of the cells. The CR data for all devices were normalized and the CR results are tabulated in Table 1. Higher monomer content resulted in the lower CR,
TABle 1: Contrast ratio for a pixel as determined from the transmission of the UV/VIS spectrophotometer.

\begin{tabular}{lrrrrrr}
\hline $\begin{array}{l}\text { Monomer content } \\
\text { (wt) }\end{array}$ & $0 \%$ & $1 \%$ & $2.5 \%$ & $5 \%$ & $10 \%$ & $20 \%$ \\
\hline CR value & $100 \%$ & $99 \%$ & $98.2 \%$ & $92.5 \%$ & $86.3 \%$ & $70.2 \%$ \\
\hline
\end{tabular}

to maintain the appropriate strength; $2.5 \sim 5 \mathrm{wt} \%$ is the best ratio range of monomer to mixture.

3.4. EO Performances of Dyed PWSLC. To achieve the colorized LC device, azo dichroic blue dye was brought in PWSLC for investigation. The most appropriate content of dye can be established by comparative analysis of polymerization in encapsulation. At the maximum appropriate content of dye, conversion of monomers should not be reduced by introduction of dye.

The structural formula of dye is given in Figure 1. Mixtures of monomer additive/photoinitiator with different contents of dye were compared with each other. Figure 6 shows the conversion of $\mathrm{C}=\mathrm{C}$ double bonds by real-time IR spectra analysis at $0.1 \mathrm{~mW} / \mathrm{cm}^{2}$, according to the UV intensity in encapsulation. With the content of dye increasing from $0 \%$ to $1 \%$, the ultimate conversion of mixture in long time UV illumination decreases, and also the reaction rate of cross-linking decreases. Compared to the nondyed mixture, the dyed samples exhibited reduced photon absorbability of photoinitiator, which need longer time to split up into free radicals. Moreover, the addition of unpolymerizable dye molecules disturbed the combination of $\mathrm{C}=\mathrm{C}$ bond with free radicals, which resulted in the slower reaction rates in dyed 


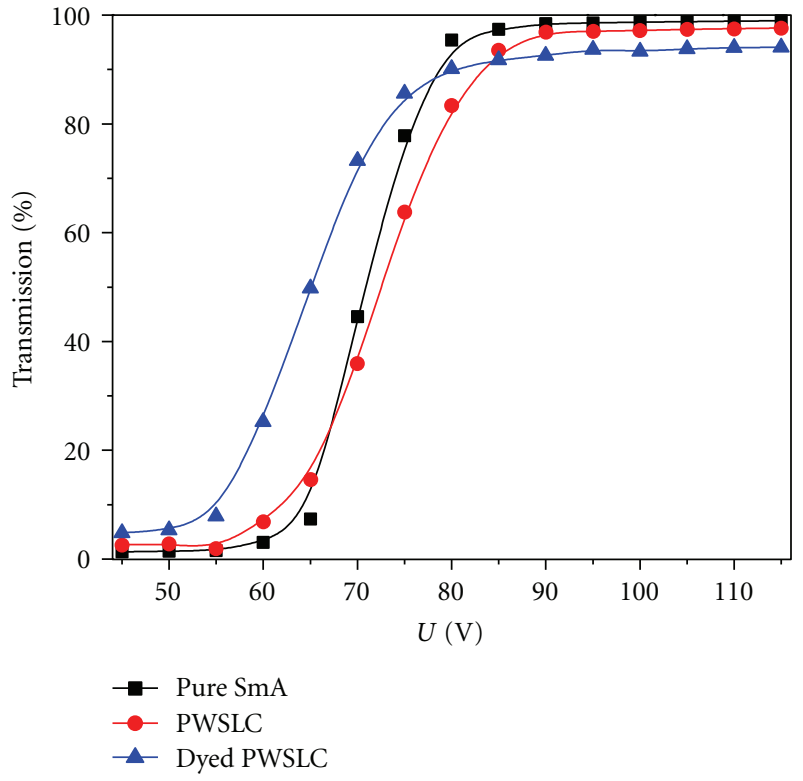

(a)

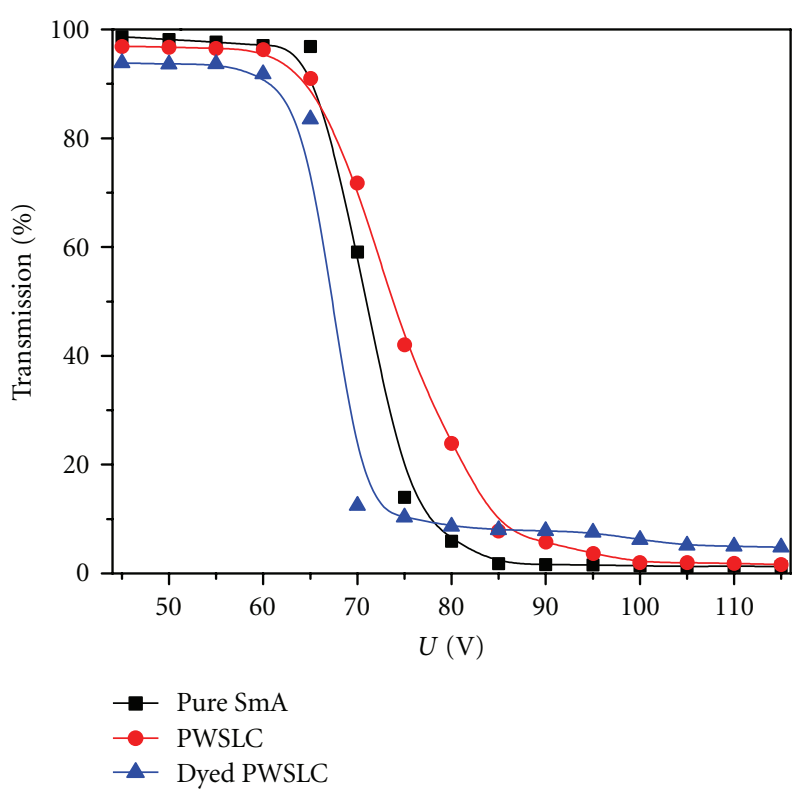

(b)

FIGURE 7: Static-response curves for pure SmA, cells with 2.5\% monomer and with/without dye for FC-HT and EHDI transitions at (a) $5 \mathrm{kHz}$ and (b) $50 \mathrm{~Hz}$, respectively.

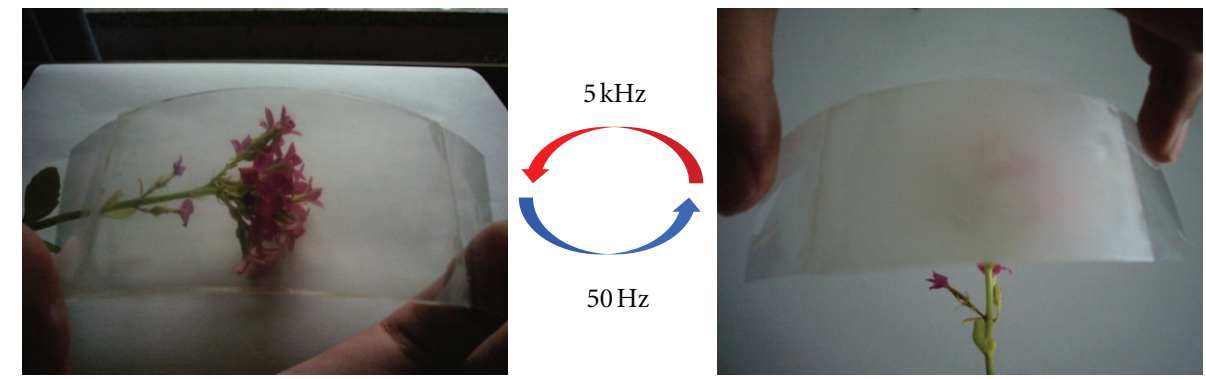

FIGURE 8: Pictures of PWSLC on flexible PET substrate; no voltage is applied to maintain their optical states.

mixtures. As shown in Figure 6, the sample with $0.2 \mathrm{wt} \%$ dye exhibited a close ultimate conversion to the nondyed one.

The mixture of LC/monomer/dye was used in encapsulation process: monomer additive mixture with $0.2 \mathrm{wt} \%$ dye was used in cell; the mixture accounted for $2.5 \mathrm{wt} \%$ of LC component. Then pure SmA cell and PWSLC cells with/without azo dichroic blue dye were compared in EO performance; the curves were shown in Figure 7. The threshold $\left(V_{\mathrm{th}}\right)$ and saturation $\left(V_{\text {sat }}\right)$ voltages were tabulated in Table 2 for both transparent and opaque states. The $V_{\text {th }}$ for FC-HT transition and EHDI were determined at the $10 \%$ change in transmission when the cell was driven by electric field, whereas $V_{\text {sat }}$ was determined at the $90 \%$ change in transmission.

As is well known, dichroic azo dyes with elongated shapes align with the LC molecules when the electric field is applied, in which the absorption transition dipole is along the long molecular axis of the dye molecule. At low frequency field application, dye molecules are randomly oriented within the focal conic texture of the SmA phase in pixels. The dichroic dye with positive dichroism used in this study was blue azo dye, which possessed very good solubility in the smectic A phase. The $0.2 \mathrm{wt} \%$ of dye was enough to provide good color to the sample cells while keeping the intrinsic properties of the host LC material [27]. The low frequency and high frequency AC square electric fields were applied to the sample cells for inducing scattering and transparent textures. Herein, we observed that the electrooptical response characteristic of PWSLC cell by the addition of dye did not chang significantly as shown in Figure 7; only $V_{\text {th }}$ and $V_{\text {sat }}$ of PWSLC cell by the addition of dye were a little lower than that of PWSLC in $5 \mathrm{kHz}$ and $50 \mathrm{~Hz}$ drives, respectively.

The transparent and opaque states of PWSLC on flexible PET substrate were shown in Figure 8, which can demonstrate the contrast effect of the bistable states by eye vision.

\section{Conclusions}

In summary, the flexible bistable SmA LC device based on polymer wall was successfully fabricated. The device 
TABLE 2: The summary of static-response measurements of pure SmA and PWSLC with/without dye at EHDI and FC-HT transition.

\begin{tabular}{lcccccc}
\hline Frequency & SmA $V_{\text {th }}$ & SmA $V_{\text {sat }}$ & PWSLC $V_{\text {th }}$ & PWSLC $V_{\text {sat }}$ & Dyed PWSLC $V_{\text {th }}$ & Dyed PWSLC $V_{\text {sat }}$ \\
\hline $5 \mathrm{kHz}$ & 64.55 & 78.49 & 62.91 & 82.51 & 56.37 & 75.34 \\
$50 \mathrm{~Hz}$ & 65.35 & 77.49 & 65.52 & 86.54 & 62.87 & 72.09 \\
\hline
\end{tabular}

composed of a polymer wall and a polymer adhesive layer structure provides flexibility and bistability, in which photolithography and UV-induced phase separation technologies were employed to form the above structure. The results demonstrated that the device exhibits very good electrooptical characteristics, high contrast ratio, and excellent stability of the states. Moreover, effect of dichroic dye on the electrooptic performances in a dyed SmA LCs flexible device was observed. The sandwich-like device presented a good flexibility and EO response; it also demonstrates the potential use of polymer walls for low-cost and light-weight flexible LC display applications. This new technology can open up new possibilities for large area display applications due to their simplicity and flexibility at low cost.

\section{Acknowledgments}

This paper was supported by National Natural Science foundation (Grant no. 50903004) and Fundamental Research Funds for the Central Universities (Grant no. ZZ1114).

\section{References}

[1] M. Schadt, "Field-effect liquid-crystal displays and liquidcrystal materials: key technologies of the 1990s," Displays, vol. 13, no. 1, pp. 11-34, 1992.

[2] J. Ma, X. Ye, and B. Jin, "Structure and application of polarizer film for thin-film-transistor liquid crystal displays," Displays, vol. 32, no. 2, pp. 49-57, 2011.

[3] H. Fujikake, H. Sato, and T. Murashige, "Polymer-stabilized ferroelectric liquid crystal for flexible displays," Displays, vol. 25, no. 1, pp. 3-8, 2004.

[4] A. Mochizuki, K. Saito, K. Ikegami, T. Narusawa, and H. Okuyama, "Study of liquid crystal materials for storagetype LCDs driven by C-MOS LSIs," Industrial \& Engineering Chemistry Product Research and Development, vol. 23, no. 4, pp. 609-612, 1984.

[5] A. Khan, I. Shiyanovskaya, T. Schneider et al., "Reflective cholesteric displays: from rigid to flexible," Journal of the Society for Information Display, vol. 13, no. 6, pp. 469-474, 2005.

[6] A. Khan, I. Shiyanovskaya, T. Schneider et al., "Progress in flexible and drapable reflective cholesteric displays," Journal of the Society for Information Display, vol. 15, no. 1, pp. 9-16, 2007.

[7] D.-K. Yang, J. L. West, L. C. Chien, and J. W. Doane, "Control of reflectivity and bistability in displays using cholesteric liquid crystals," Journal of Applied Physics, vol. 76, no. 2, pp. 1331-1333, 1994.

[8] H. Yoshida, Y. Takizawa, T. M. Martin, and J. L. West, "Reflective display with photoconductive layer and bistable reflective cholesteric mixture," Journal of the Society for Information Display, vol. 5, no. 3, pp. 269-274, 1997.
[9] J. Rudin, S. Kitson, and A. Geisow, "Color plastic bistable nematic display fabricated by imprint and ink-jet technology," Journal of the Society for Information Display, vol. 17, no. 4, pp. 309-316, 2009.

[10] D. J. Gardiner, C. J. Davenport, J. Newton, and H. J. Coles, "Electro-optic bistability in organosiloxane bimesogenic liquid crystals," Journal of Applied Physics, vol. 99, no. 11, Article ID 113517, 2006.

[11] D. J. Gardiner, S. M. Morris, and H. J. Coles, "High-efficiency multistable switchable glazing using smectic A liquid crystals," Solar Energy Materials and Solar Cells, vol. 93, no. 3, pp. 301306, 2009.

[12] E. P. Raynes and C. M. Waters, "Supertwisted nematic liquid crystal displays," Displays, vol. 8, no. 2, pp. 59-63, 1987.

[13] Y. J. Lee, S. J. Jang, J. W. Jung et al., "Mechanical stability of Pixel-Isolated liquid crystal mode for flexible display application," Molecular Crystals and Liquid Crystals, vol. 458, no. 1, pp. 81-87, 2006.

[14] S.-J. Jang, J.-W. Jung, H.-R. Kim, M. Y. Jin, Y.-J. Lee, and J.-H. Kim, "Pixel-isolated liquid-crystal mode by using a patterned anisotropic phase separation for flexible LCDs," Journal of the Society for Information Display, vol. 15, no. 2, pp. 119-125, 2007.

[15] Y.-T. Kim, J.-H. Hong, T.-Y. Yoon, and S.-D. Lee, "Pixelencapsulated flexible displays with a multifunctional elastomer substrate for self-aligning liquid crystals," Applied Physics Letters, vol. 88, no. 26, Article ID 263501, 2006.

[16] J.-W. Jung, M. Y. Jin, H.-R. Kim, Y.-J. Lee, and J.-H. Kim, "Mechanical stability of pixel-isolated liquid crystal mode with plastic substrates," Japanese Journal of Applied Physics, vol. 44, no. 12, pp. 8547-8551, 2005.

[17] R. Penterman, S. I. Klink, H. De Koning, G. Nisato, and D. J. Broer, "Single-substrate liquid-crystal displays by photoenforced stratification," Nature, vol. 417, no. 6884, pp. 55-58, 2002.

[18] M. Mucha, "Polymer as an important component of blends and composites with liquid crystals," Progress in Polymer Science, vol. 28, no. 5, pp. 837-873, 2003.

[19] S.-J. Sung, E.-A. Jung, D.-H. Son, D.-H. Kim, J.-K. Kang, and K. Y. Cho, "The effect of bi-component acrylate prepolymers on the phase separation and electro-optical properties of pixelisolated liquid crystals," Displays, vol. 32, no. 5, pp. 334-337, 2011.

[20] D. T. McCormick, R. Chavers, and C. A. Guymon, "Investigation of polymer nanostructure evolution during the formation of polymer/smectic liquid crystal composites," Macromolecules, vol. 34, no. 20, pp. 6929-6935, 2001.

[21] V. Vorflusev and S. Kumar, "Phase-separated composite films for liquid crystal displays," Science, vol. 283, no. 5409, pp. 1903-1905, 1999.

[22] Y. Kim, J. Francl, B. Taheri, and J. L. West, "A method for the formation of polymer walls in liquid crystal/polymer mixtures," Applied Physics Letters, vol. 72, no. 18, pp. 22532255, 1998.

[23] N. Gheorghiu, J. L. West, A. V. Glushchenko, and M. Mitrokhin, "Patterned field induced polymer walls for smectic 
A bistable flexible displays," Applied Physics Letters, vol. 88, no. 26, Article ID 263511, 2006.

[24] E. A. Büyüktanir, N. Gheorghiu, J. L. West, M. Mitrokhin, B. Holter, and A. Glushchenko, "Field-induced polymer wall formation in a bistable smectic-A liquid crystal display," Applied Physics Letters, vol. 89, no. 3, Article ID 031101, 2006.

[25] J. Newton, H. Coles, P. Hodge, and J. Hannington, "Synthesis and properties of low-molar-mass liquid-crystalline siloxane derivatives," Journal of Materials Chemistry, vol. 4, no. 6, pp. 869-874, 1994.

[26] D. J. Gardiner and H. J. Coles, "Highly anisotropic conductivity in organosiloxane liquid crystals," Journal of Applied Physics, vol. 100, no. 12, Article ID 124903, 2006.

[27] S. Khosla, K. K. Raina, and H. J. Coles, "Electrically induced storage effects in smectic A phase of dyed low molar mass siloxane liquid crystals," Current Applied Physics, vol. 3, no. 23, pp. 135-140, 2003. 

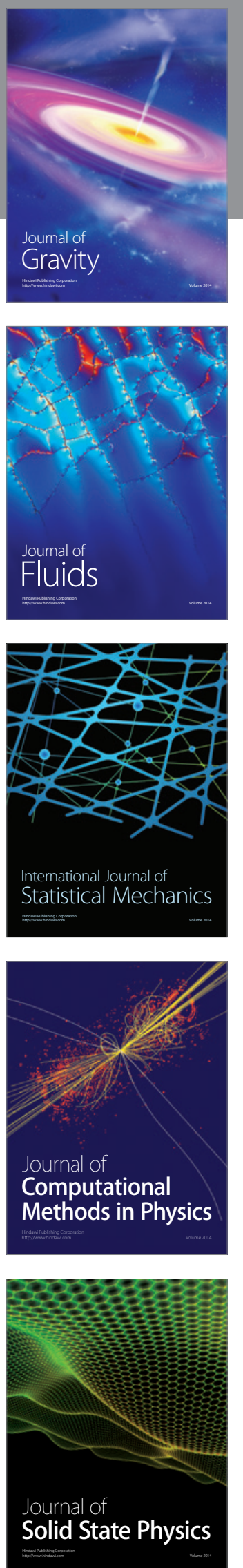

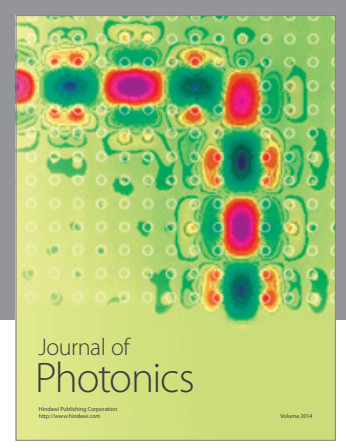

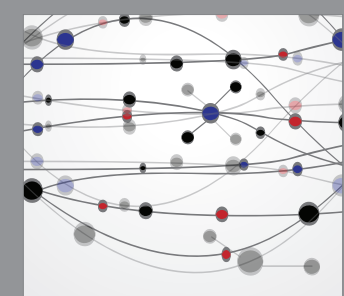

The Scientific World Journal
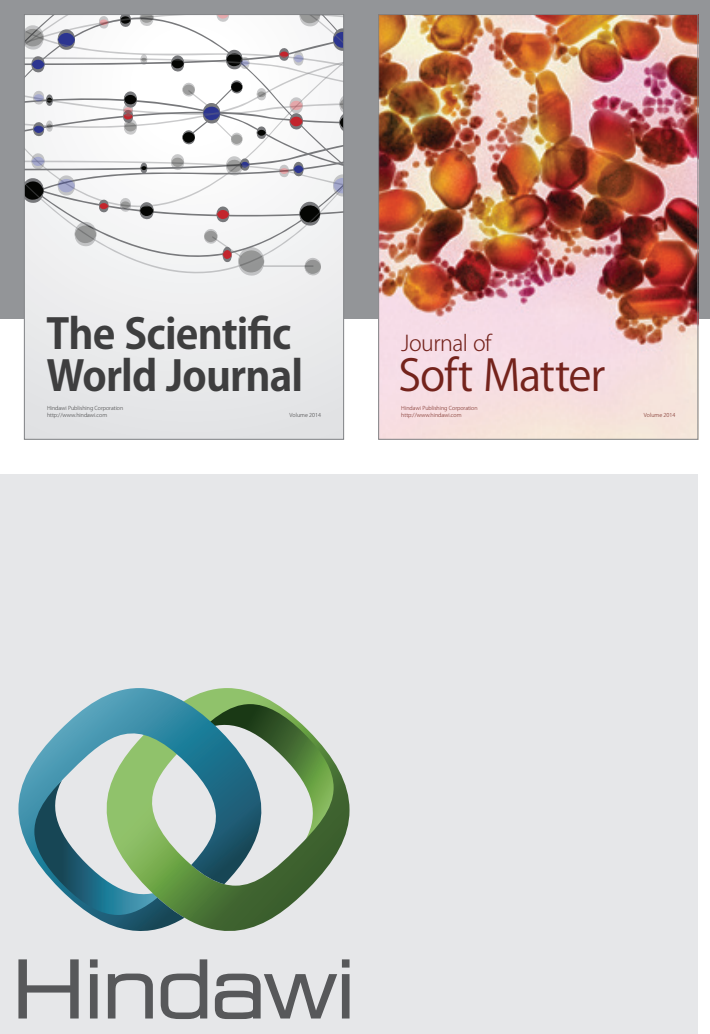

Submit your manuscripts at

http://www.hindawi.com
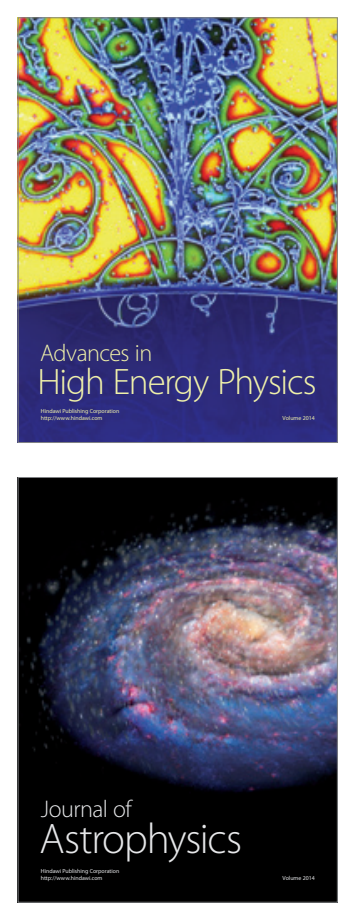
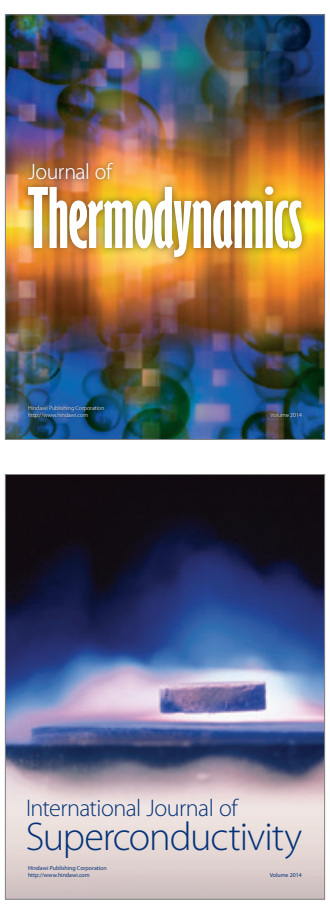
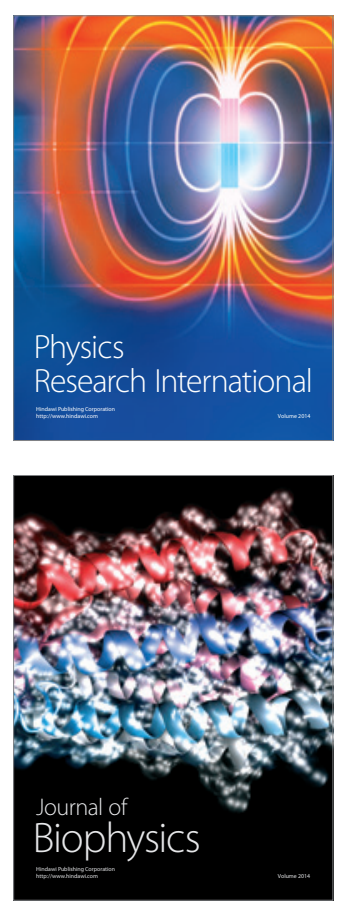
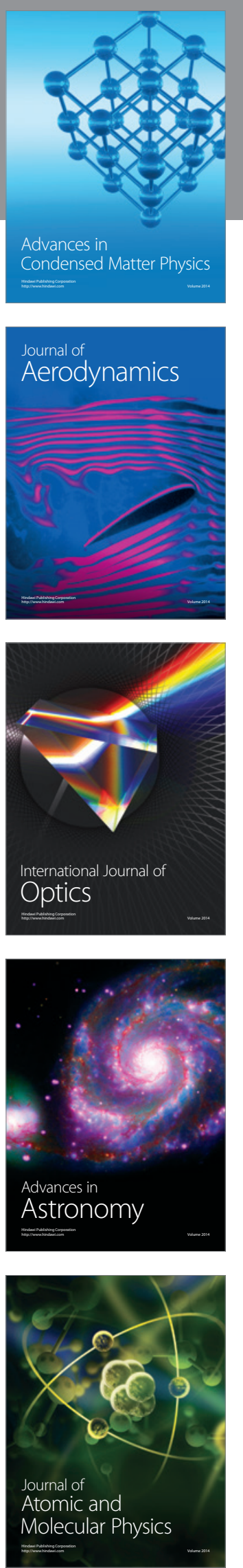